OPEN ACCESS

Edited by:

Björn Tampe,

University Medical Center

Göttingen, Germany

Reviewed by:

Yun Long,

Peking Union Medical College

Hospital (CAMS), China

Lars-Olav Harnisch,

University Medical Center

Goettingen, Germany

*Correspondence:

William David Freeman

freeman.william1@mayo.edu

Specialty section: This article was submitted to Intensive Care Medicine and Anesthesiology,

a section of the journal

Frontiers in Medicine

Received: 04 October 2021 Accepted: 28 December 2021

Published: 17 February 2022

Citation:

Bansal V, Smischney NJ, Kashyap $R$

Li Z, Marquez A, Diedrich DA,

Siegel JL, Sen A, Tomlinson AD,

Venegas-Borsellino $C P$ and

Freeman WD (2022) Reintubation

Summation Calculation: A Predictive

Score for Extubation Failure in

Critically III Patients.

Front. Med. 8:789440.

doi: 10.3389/fmed.2021.789440

\section{Reintubation Summation Calculation: A Predictive Score for Extubation Failure in Critically III Patients}

\author{
Vikas Bansal 1,2, Nathan J. Smischney ${ }^{2,3}$, Rahul Kashyap ${ }^{2,3}$, Zhuo Li ${ }^{4}$, Alberto Marquez ${ }^{3}$, \\ Daniel A. Diedrich ${ }^{2,3}$, Jason L. Siegel $5,6,7$, Ayan Sen ${ }^{8,9}$, Amanda D. Tomlinson ${ }^{5}$, \\ Carla P. Venegas-Borsellino ${ }^{5}$ and William David Freeman ${ }^{5,6,7 *}$ \\ ${ }^{1}$ Division of Pulmonary and Critical Care Medicine, Department of Medicine, Mayo Clinic, Rochester, MN, United States, \\ ${ }^{2}$ Critical Care Independent Multidisciplinary Program, Mayo Clinic, Rochester, MN, United States, ${ }^{3}$ Department of \\ Anesthesiology and Perioperative Medicine, Mayo Clinic, Rochester, MN, United States, ${ }^{4}$ Biostatistics Unit, Mayo Clinic, \\ Jacksonville, FL, United States, ${ }^{5}$ Department of Critical Care Medicine, Mayo Clinic, Jacksonville, FL, United States, \\ ${ }^{6}$ Department of Neurologic Surgery, Mayo Clinic, Jacksonville, FL, United States, ${ }^{7}$ Department of Neurology, Mayo Clinic, \\ Jacksonville, FL, United States, ${ }^{8}$ Department of Critical Care Medicine, Mayo Clinic Hospital, Phoenix, AZ, United States, \\ ${ }^{9}$ Department of Neurologic Surgery, Mayo Clinic Hospital, Phoenix, AZ, United States
}

Objective: To derive and validate a multivariate risk score for the prediction of respiratory failure after extubation.

Patients and methods: We performed a retrospective cohort study of adult patients admitted to the intensive care unit from January 1, 2006, to December 31, 2015, who received mechanical ventilation for $\geq 48 \mathrm{~h}$. Extubation failure was defined as the need for reintubation within $72 \mathrm{~h}$ after extubation. Multivariate logistic regression model coefficient estimates generated the $\mathbf{R e}$-Intubation Summation Calculation (RISC) score.

Results: The 6,161 included patients were randomly divided into 2 sets: derivation $(n=3,080)$ and validation $(n=3,081)$. Predictors of extubation failure in the derivation set included body mass index $<18.5 \mathrm{~kg} / \mathrm{m}^{2}$ [odds ratio (OR), 1.91; $95 \% \mathrm{Cl}, 1.12-3.26$; $P=0.02$ ], threshold of Glasgow Coma Scale of at least 10 (OR, 1.68; 95\% Cl, 1.31-2.16; $P<0.001$ ), mean airway pressure at 1 min of spontaneous breathing trial $<10 \mathrm{cmH}_{2} \mathrm{O}$ (OR, 2.11; 95\% Cl, 1.68-2.66; $P<0.001$ ), fluid balance $\geq 1,500 \mathrm{~mL} 24 \mathrm{~h}$ preceding extubation (OR, 2.36; 95\% Cl, 1.87-2.96; $P<0.001$ ), and total mechanical ventilation days $\geq 5$ (OR, 3.94; 95\% Cl 3.04-5.11; $P<0.001)$. The $\mathrm{C}$-index for the derivation and validation sets were $0.72(95 \% \mathrm{Cl}, 0.70-0.75)$ and $0.72(95 \% \mathrm{Cl}, 0.69-0.75)$. Multivariate logistic regression demonstrated that an increase of 1 in RISC score increased odds of extubation failure 1.6-fold (OR, 1.58; 95\% Cl, 1.47-1.69; $P<0.001)$.

Conclusion: RISC predicts extubation failure in mechanically ventilated patients in the intensive care unit using several clinically relevant variables available in the electronic medical record but requires a larger validation cohort before widespread clinical implementation.

Keywords: critical care medicine, extubation failure, intensive care unit, mechanical ventilation, reintubation, predictive modeling, prediction scale 


\section{INTRODUCTION}

Before extubating a mechanically ventilated patient, intensivists must evaluate the patient's risk of extubation failure (EF). This decision is usually based on the results of a rapid shallow breathing index (RSBI), which is most often assessed during the readiness evaluation to identify patients who may proceed with the spontaneous breathing trial (SBT), with either a T-piece or low-level pressure support (1-3). The RSBI is the ratio of respiratory frequency to tidal volume and is a commonly used weaning predictor (1-3). This method is not $100 \%$ predictive of extubation success (ES) by $72 \mathrm{~h}$. The decision-making behind extubation is critically important, as failed extubation occurs in $10-20 \%$ of intensive care unit (ICU) patients $(4,5)$ and both delayed extubation as well as early extubation are associated with worse outcomes. Extubation delay is associated with ventilatorassociated pneumonia $(6,7)$, increased length of stay, increased risk for downstream tracheostomy $(8,9)$ and increased mortality in brain-injured patients (8). Extubation failure after planned extubation is associated with adverse outcomes including increased hospital mortality, prolonged hospital stay, higher costs, and greater need for tracheotomy and transfer to post-acute care (10-13).

While there are numerous ventilator weaning predictors and types of SBTs $(14,15)$, there is a paucity of data on risk factors that predict EF prior to removal of the endotracheal tube. Predicting factors for ES and EF include amount of endotracheal secretions $(8,16,17)$, cough strength $(16,18,19)$, and mental status prior to extubation after a successful SBT $(16,20)$. Patients with moderate or abundant secretions have been 3-8 times more likely to fail extubation than those with few to no secretions $(8,19)$. Coplin et al. (16) stated that the Glasgow coma scale (GCS) score alone did not predict extubation outcome in brain-injured patients and should not be used to exclude extubation; however, other investigators reported that impaired mental status did predict $\mathrm{EF}(21,22)$. Moreover, patients who fail extubation often retain carbon dioxide because of an imbalance among respiratory muscle strength and imposed load (1,23-25). Patients extubated while developing hypercapnia $\left(\mathrm{PaCO}_{2}>45 \mathrm{mmHg}\right)$ during a successful SBT may also have an increased risk of mortality due to respiratory failure compared to those who do not develop hypercapnia during SBT (2).

Therefore, we hypothesized that recurrent respiratory failure requiring reintubation after initial extubation could be estimated using a composite score of known risk factors available in the electronic medical record (EMR). Our main objective was to derive a simple clinical prediction tool using a multivariate model and validate the Re-Intubation Scale Calculation (RISC) score to predict respiratory failure requiring reintubation.

\footnotetext{
Abbreviations: ARDS, acute respiratory distress syndrome; AUC, area under the curve; EF, extubation failure; ES, extubation success; FOUR, Full Outline of UnResponsiveness; GCS, Glasgow coma scale; ICU, intensive care unit; MAP, mean airway pressure; OR, odds ratio; RISC, Reintubation Scale Calculation; RSBI, rapid shallow breathing index; SBT, spontaneous breathing trial.
}

\section{METHODS}

\section{Study Population}

We performed a retrospective cohort study to develop and validate the RISC score. Our study population included critically ill adults who were on mechanical ventilation for $\geq 48 \mathrm{~h}$ during their stay in a medical, surgical, or mixed ICU between January 1, 2006, and December 31, 2015 (Figure 1). The study was approved by the Mayo Clinic Institutional Review Board for the use of existing medical records of patients with prior research authorization.

\section{Inclusion Criteria}

We gathered data for patients who met the following criteria: age $\geq 18$ years; intubation and mechanical ventilation for $\geq 48 \mathrm{~h}$; adequate oxygenation, suggested by $\mathrm{PaO}_{2}>60 \mathrm{mmHg}$ at fraction of inspired oxygen of $\leq 0.4$ with an extrinsic positive endexpiratory pressure (PEEP) $<7 \mathrm{cmH}_{2} \mathrm{O}$; successful SBT of $60 \mathrm{~min}$ and treating physician approval for extubation; cardiovascular stability (i.e., absence of active myocardial ischemia, heart rate $<130$ beats per min, absence of vasopressor use, and dopamine or dobutamine $<5 \mathrm{mcg} / \mathrm{kg} / \mathrm{min}$ ); body temperature between $36^{\circ} \mathrm{C}$ and $38^{\circ} \mathrm{C}$; serum hemoglobin $\geq 8 \mathrm{~g} / \mathrm{dL}$; adequate coughing during suctioning and suction frequency of no more than every $2 \mathrm{~h}$; and baseline cough observed by airway care score during suctioning (8). We excluded patients with missing baseline variables, those who failed SBT, those with tracheostomies, and those who withdrew all support or received comfort care support after extubation.

\section{Outcome Classification}

Patients were grouped by ES or EF. ES was defined as the ability to maintain spontaneous unassisted respiration for $\geq 72 \mathrm{~h}$ after extubation. EF was defined as reintubation within $72 \mathrm{~h}$ after extubation.

\section{Data Collection}

We collected data retrospectively by using Mayo Clinic ICU DataMart and Unified Data Platform, which are extensive data repositories that contain a near real time standardized replica of Mayo Clinic's EMR. These databases contain patient clinical information along with their laboratory test results, respiratory therapy notes, mechanical ventilation data, medications, vital sign flowsheets, and other clinical and pathological information from sources within the institution and have been previously validated (26). ICU Datamart stored validated ICU ventilator data at 15-min intervals and 2 min intervals in a surgical setting. The validation of ventilator data was done by the respiratory therapist and recorded in EMR.

Patient data collected included age, Acute Physiology and Chronic Health Evaluation score, mechanical ventilation duration, history of chronic comorbidities, hemoglobin and blood chemistries, arterial blood gas values within $1 \mathrm{~h}$ after onset of SBT, date and time of extubation, use of drugs (e.g., paralytics, systemic corticosteroids, etc.) during mechanical ventilation, negative inspiratory pressure measured prior to SBT, and GCS score assessed by the patient's nurse at the time of extubation. The airway care score (8) was recorded if available. Additionally, 


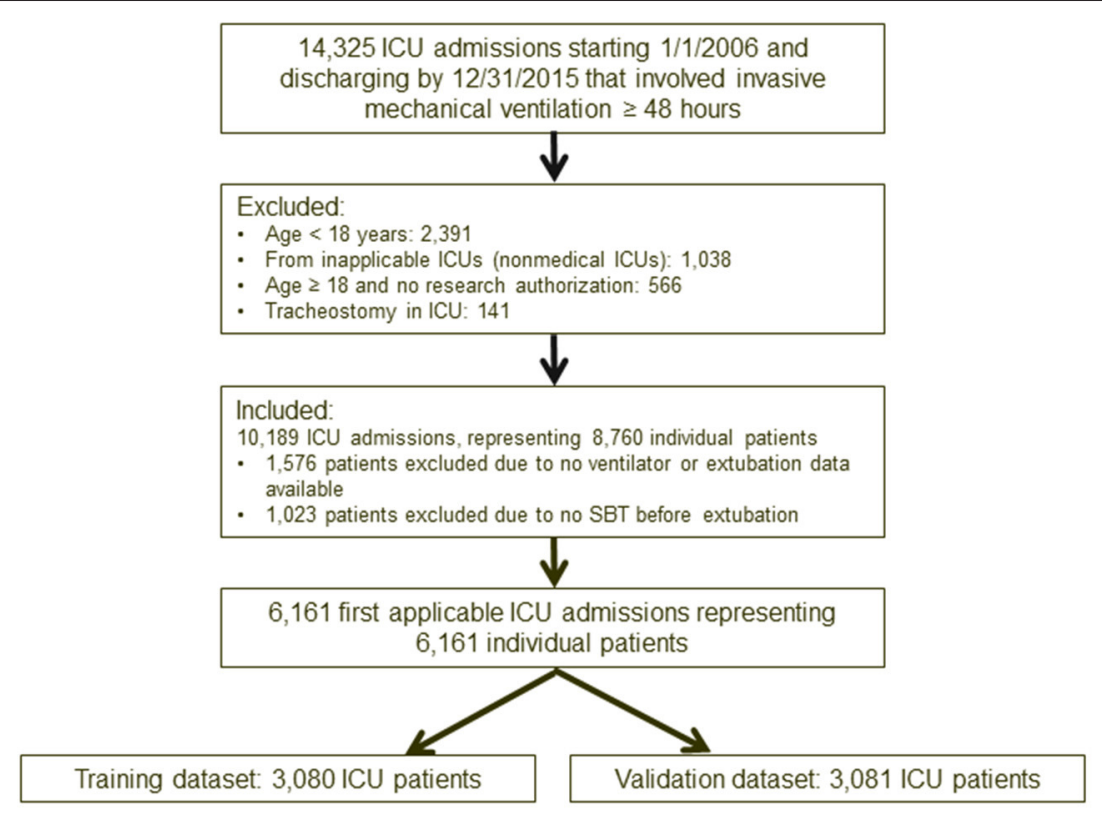

ICU, intensive care unit; SBT, spontaneous breathing trial

FIGURE 1 | Flowchart of study participants. ICU, intensive care unit; SBT, spontaneous breathing trial.

we collected data on respiratory variables including minute ventilation, respiratory rate, tidal volume, and at 1,30 , and 60 min during the SBT. We also collected RSBI recorded at $1 \mathrm{~min}$ (RSBI1), $30 \mathrm{~min}$ (RSBI30), and $60 \mathrm{~min}$ (RSBI60) during the SBT. We evaluated 2 pre-defined variables: (1) the RSBI30 to RSBI1 ratio as a percentage reflecting the change of RSBI from baseline to $30 \mathrm{~min}$ and (2) the RSBI60 to RSBI1 ratio as a percentage reflecting the change of RSBI from baseline to $60 \mathrm{~min}$.

\section{Data Analysis}

The main outcome of interest was EF. Categorical variables were reported as frequency and percentage and continuous variables as mean \pm standard deviation (SD) and median (25th, 75th). We used the Wilcoxon rank sum test to compare continuous and ordinal variables between patients with and without EF, and $\chi^{2}$ or Fisher exact tests to compare categorical variable correlations. We used odds ratios (ORs) and 95\% CIs to express a variable's strength for independently predicting EF in multivariate logistic regression models. Extreme outliers for variables $\geq 3 \mathrm{SD}$ were verified manually in EMR. If the value was not available in the EMR, then we considered these erroneous values as missing in the final analysis. Probable predictor variables were chosen based on our clinical experience and information from other studies (11,20,27-36). Predictor variables that were significantly different between the success and failure groups $(P \leq 0.01)$ for which no more than $5 \%$ data were missing were included in multivariate analysis. Variable reduction was done based on the correlation between predictors and the threshold used was
0.6. Prediction scores were developed based on the multivariate logistic regression model coefficient estimate. The smallest coefficient was first identified and assigned a score of 1 . Then the scores for the other variables were equal to their corresponding model coefficients divided by this smallest coefficient and finally, all scores were rounded to integers. We developed the RISC score by assigning an amount to each of the risk factors based on their model coefficients. Discrimination of the score as a continuous variable was reported as C-index. Area under the curve (AUC) was also reported for scores at different cutoff points. Calibration of the score was evaluated by calibration plot comparing the predicted and observed risk of EF within $72 \mathrm{~h}$. All statistical tests were 2-sided, with an $\alpha$-level of 0.05 for statistical significance. Analysis was done using SAS version 9.4 (SAS Institute Inc.).

\section{RESULTS}

The 6,161 patients included in our study were randomly allocated into a derivation set $(n=3,080)$ and validation set $(n=3,081)$. In the derivation set, patients had a mean (SD) age of 61.7 (16.6) years, and 1,820 (59\%) were men. Within $72 \mathrm{~h}, 393$ patients (12.8\%) experienced EF. Similarly, in the validation set, the mean (SD) age was 62.4 (16.6) years and 1,778 (58\%) were men. Within 72 h, 353 patients (11.5\%) experienced EF (Table 1). Patient endotracheal secretions, mechanical ventilation, and ICU admission diagnosis data for both sets are displayed in Appendices A-C. 
TABLE 1 | Baseline demographic and hemodynamic instability and fluid status.

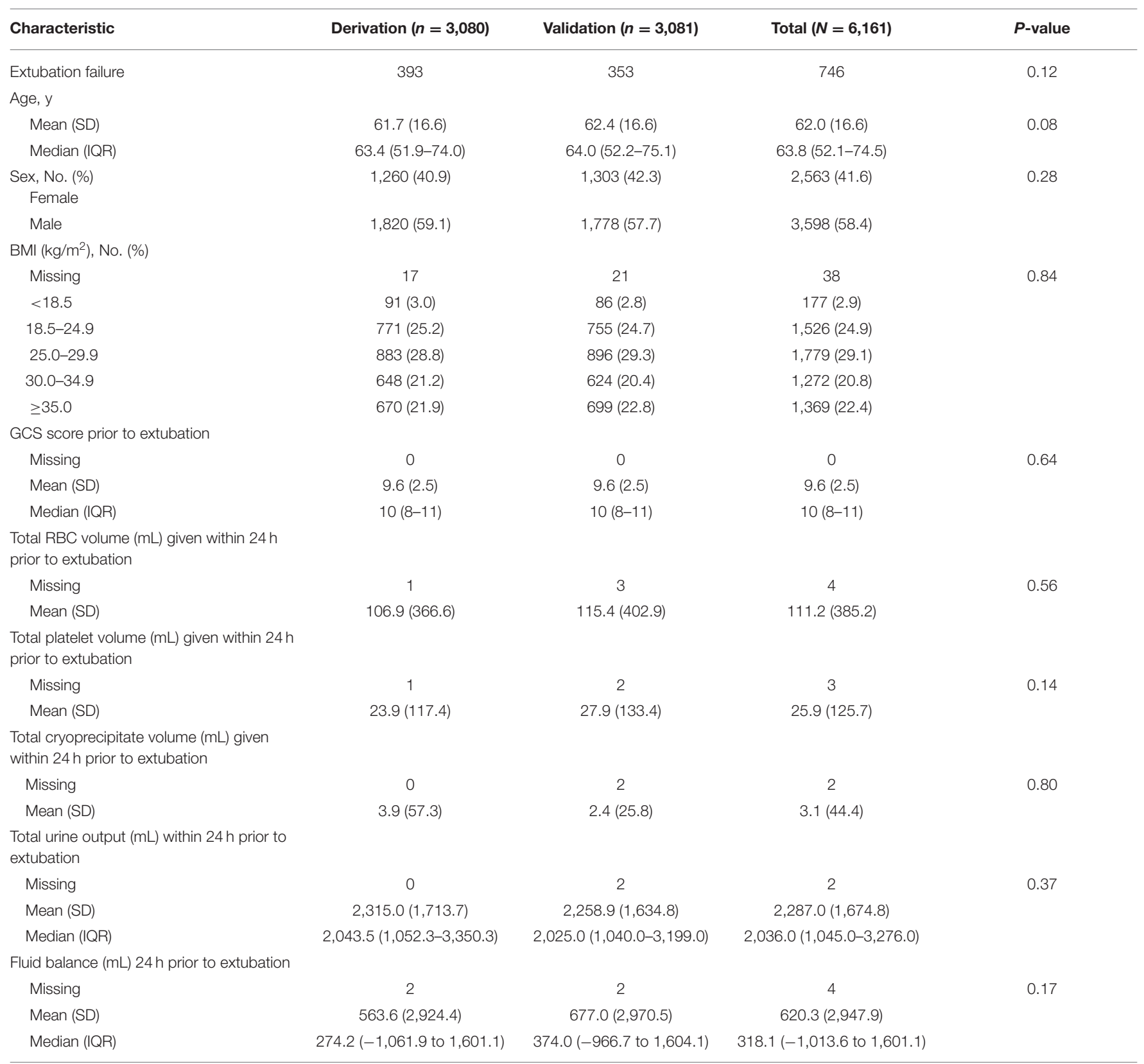

BMI, body mass index; GCS, Glasgow coma scale; IQR, interquartile range; RBC, red blood cell; $S D$, standard deviation.

Predictors of EF in the derivation set included underweight status (body mass index, $<18.5 \mathrm{~kg} / \mathrm{m}^{2}$; OR, $1.91 ; 95 \% \mathrm{CI}, 1.12-$ 3.26 ; $P=0.02$ ), GCS score of $\geq 10$ (OR, 1.68 ; 95\% CI, $1.31-$ 2.16; $P<0.001$ ), mean airway pressure (MAP) closest to $1 \mathrm{~min}$ after SBT start within $15 \mathrm{~min}<10 \mathrm{cmH}_{2} \mathrm{O}(\mathrm{OR}, 2.11$; 95\% CI, 1.68-2.66; $P<0.001$ ), fluid balance of $\geq 1,500 \mathrm{~mL} 24 \mathrm{~h}$ prior to extubation (OR, 2.36; 95\% CI, 1.87-2.96; $P<0.001$ ), and mechanical ventilation $\geq 5$ days (OR, 3.94; 95\% CI, 3.04-5.11; $P$ $<0.001$ ) (Tables 2, 3). The derivation set had a C-index of 0.72 (95\% CI, 0.70-0.75) (Figure 2).

Our logistic model in validation set demonstrated that as RISC increased by 1, the odds of having EF became 1.6-fold higher (OR, 1.58; 95\% CI, 1.47-1.69; $P \leq 0.001$ ) (Table 4). Receiving operating curve analysis revealed the best cutoff for RISC was 4, which demonstrated a sensitivity of 0.80 and specificity of 0.54 with AUC of 0.67 (95\% CI, 0.65-0.69) (Appendix C). Calibration plot of observed vs. predicted EF in the validation set is displayed in Figure 3. Using the above model, the validation set had a Cindex of 0.72 (95\% CI, 0.69-0.75). The RISC score ranged from 0 to 8 with a median of 4 (Figure 4 ).

\section{DISCUSSION}

We successfully developed a multivariable RISC score to predict extubation failure after a successful SBT with readily available bedside predictors. The RISC score predicts extubation failure 
TABLE 2 | SBT and MV data for derivation and validation cohort.

\begin{tabular}{|c|c|c|c|c|}
\hline Characteristic & Derivation $(n=3,080)$ & Validation $(n=3,081)$ & Total $(N=6,161)$ & $P$-value \\
\hline \multicolumn{5}{|c|}{ Total ventilation hours } \\
\hline Missing & 0 & 1 & 1 & 0.22 \\
\hline Mean (SD) & $192.4(194.4)$ & $187.8(189.7)$ & $189.6(191.9)$ & \\
\hline Median (IQR) & $131.4(79.5-230.7)$ & $127.6(75.3-221.2)$ & $129.0(76.5-225.0)$ & \\
\hline \multicolumn{5}{|c|}{ Respiratory rate (breaths/min) closest to 1 min after SBT start within 15 min } \\
\hline Median (IQR) & $20.0(15.0-25.0)$ & $19.0(15.0-24.4)$ & $19.2(15.0-25.0)$ & \\
\hline \multicolumn{5}{|c|}{ Expired $V_{T}$ (in $\mathrm{ml}$ ) closest to $1 \mathrm{~min}$ after SBT start within $15 \mathrm{~min}$} \\
\hline Missing & 123 & 130 & 253 & 0.34 \\
\hline Mean (SD) & $517.9(204.3)$ & $512.6(198.7)$ & $515.3(201.5)$ & \\
\hline Median (IQR) & $489.0(389.0-620.0)$ & $480.0(386.0-601.0)$ & $480.0(388.0-610.0)$ & \\
\hline Median (IQR) & $6(4.7-7.7)$ & $5.9(4.5-7.6)$ & $5.9(4.6-7.6)$ & \\
\hline \multicolumn{5}{|c|}{$\mathrm{RSB}^{\mathrm{a}}$ (breaths/min/L) closest to 1 min after SBT start within $15 \mathrm{~min}$} \\
\hline Missing & 121 & 126 & 247 & 0.98 \\
\hline Mean (SD) & $50.6(44.3)$ & $49.9(41.3)$ & $50.3(42.9)$ & \\
\hline Median (IQR) & $40.0(26.2-61.5)$ & $40.8(26.4-60.6)$ & $40.4(26.3-60.9)$ & \\
\hline \multicolumn{5}{|c|}{ MAP $\left(\mathrm{cmH}_{2} \mathrm{O}\right)$ closest to $1 \mathrm{~min}$ after SBT start within $15 \mathrm{~min}$} \\
\hline Missing & 31 & 45 & 76 & 0.75 \\
\hline Mean (SD) & $10.7(3.6)$ & $10.8(3.7)$ & $10.8(3.6)$ & \\
\hline Median (IQR) & $10.0(7.8-13.0)$ & $9.9(7.8-13.0)$ & $9.9(7.8-13.0)$ & \\
\hline \multicolumn{5}{|c|}{ PIP $\left(\mathrm{cmH}_{2} \mathrm{O}\right)$ closest to $1 \mathrm{~min}$ after SBT start within $15 \mathrm{~min}$} \\
\hline Missing & 129 & 156 & 285 & 0.43 \\
\hline Missing & 0 & 0 & 0 & 0.53 \\
\hline Mean (SD) & $7.5(3.2)$ & $7.5(3.3)$ & $7.5(3.2)$ & \\
\hline Median (IQR) & $5(5-10)$ & $5(5-10)$ & $5(5-10)$ & \\
\hline \multicolumn{5}{|c|}{ PS $\left(\mathrm{mmH}_{2} \mathrm{O}\right)$ closest to $1 \mathrm{~min}$ after SBT start within $15 \mathrm{~min}$} \\
\hline Missing & 6 & 9 & 15 & 0.96 \\
\hline Mean (SD) & $8.9(4.0)$ & $8.8(3.5)$ & $8.9(3.8)$ & \\
\hline Median (IQR) & $10(5-10)$ & $10(5-10)$ & $10(5-10)$ & \\
\hline \multicolumn{5}{|c|}{ History of paralytic use, No. (\%) } \\
\hline No & $1,096(35.6)$ & $1,145(37.2)$ & $2,241(36.4)$ & 0.20 \\
\hline Yes & $1,984(64.4)$ & $1,936(62.8)$ & $3,920(63.6)$ & \\
\hline \multicolumn{5}{|c|}{ History of sedative use, No. (\%) } \\
\hline No & $202(6.6)$ & $232(7.5)$ & $434(7.0)$ & 0.15 \\
\hline Yes & 2,878 (93.4) & 2,849 (92.5) & $5,727(93.0)$ & \\
\hline
\end{tabular}

IQR, interquartile range; MAP, mean airway pressure; MV, mechanical ventilation; PEEP, positive end-expiratory pressure; PIP, peak inspiratory pressure; PS, Pressure Support; RSBI, rapid shallow breathing index; $S B T$, spontaneous breathing trial; $S D$, Standard deviation; $V_{T}$, tidal volume. ${ }^{a} R S B I$, respiratory rate (f) in breaths/min/ $V_{T}$ in $L$. 
TABLE 3 | Logistic regression model predicting extubation failure.

\begin{tabular}{|c|c|c|c|c|c|c|}
\hline Variable & Label & \multicolumn{2}{|c|}{ Univariable } & \multicolumn{2}{|c|}{ Multivariate } & Score \\
\hline GCS10 & GCS score prior to CPAP mode $\geq 10$ & $1.61(1.27-2.05)$ & $<0.001$ & $1.68(1.31-2.16)$ & $<0.001$ & 1 \\
\hline MAP10 & MAP closest to 1 min after SBT start within 15 min $<10$ & $1.71(1.38-2.13)$ & $<0.001$ & $2.11(1.68-2.66)$ & $<0.001$ & 1 \\
\hline Fluid balance & Fluid balance $24 \mathrm{~h}$ prior to extubation $\geq 1,500$ & $2.30(1.85-2.86)$ & $<0.001$ & $2.36(1.87-2.96)$ & $<0.001$ & 2 \\
\hline
\end{tabular}

CPAP, continuous positive airway pressure; GCS, Glasgow coma scale; MAP, mean airway pressure; OR, odds ratio; SBT, spontaneous breathing trial.

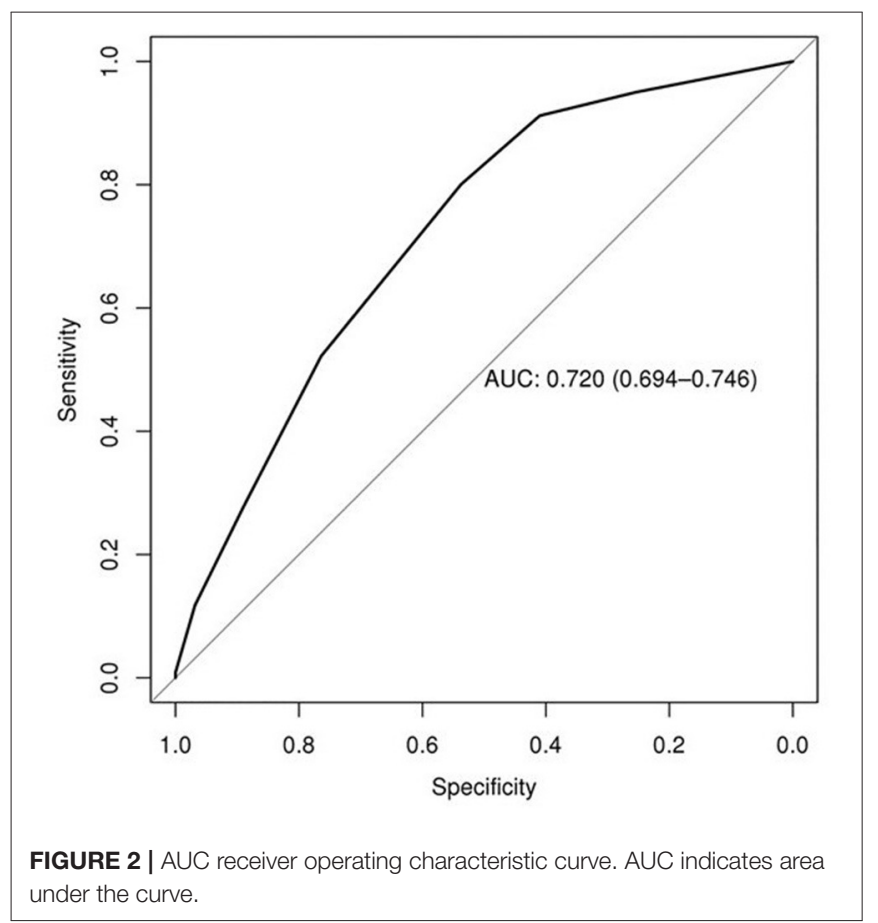

TABLE 4 | Validation set: extubation within 72 h predicted by score.

\begin{tabular}{llll}
\hline Variable & OR $(\mathbf{9 5 \%} \mathbf{C l})$ & $\boldsymbol{P}$-value & C-index \\
\hline RISC score & $1.58(1.47-1.69)$ & $<0.001$ & 0.72 \\
\hline
\end{tabular}

OR, odds ratio; RISC, Reintubation Summation Calculation.

with the best cut-off at $\geq 4$ demonstrating a sensitivity of 0.80 and a specificity of 0.54 with AUC of 0.67 . This is a modest value to determine extubation failure. RISC score provides several multivariate risk factors that can be externally validated in future deep learning and machine learning predictive models. We acknowledge this model is limited and some would argue that a clinically useful tool should have a higher AUC; however, external testing with larger data sets may be helpful in reproducing these results.

Neurologic impairment was found to be a possible risk factor for EF in our study and was validated previously in several studies
(16, 19, 37-39). Mokhlesi et al. (37) verified that a moderate GCS score (9-12) can clinically predict reintubation, comparable to our results. We feel this is an important finding for clinicians caring for those patients with an "intermediate" GCS in their decision-making for extubation. GCS is inherently limited in finding lower cutoffs since a "V1-NT" is the subcomponent reported in intubated patients. Moreover, its components only grade Eyes (E1-4) and Motor (M1-6) which if maximal total 10 points (E4+M6), similar to our observed lowest cutoff. Some suggest using the Full Outline of UnResponsiveness (FOUR) score (40) might provide a more granular range $(0-16)$ by including brainstem cranial nerve findings. We reviewed our data for FOUR score (40), but only had 228 patients, which is statistically underpowered to detect lower limits of this coma scale for reintubation risk. Only a future study using FOUR score with sufficient sample size may be able to detect this as a true reintubation risk, or in a future randomized trial in brain-injured patients similar to the one performed by WDF, which previously showed no difference in reintubation rates in GCS 10 or less patients with intact brainstem protective reflexes of cough/gag (9). We find documentation of protective airway or cranial nerve reflexes lacking in most and/or all coma scales, even in the FOUR score which focuses on pupillary reflexes for the brainstem. Furthermore, the FOUR score did not include gag/cough reflexes in the randomized trial by Manno et al. (9).

Another covariate of the RISC score is a MAP closest to $1 \mathrm{~min}$ after SBT start within $15 \mathrm{~min}<10 \mathrm{cmH}_{2} \mathrm{O}$. MAP is dependent on peak inspiratory pressure, PEEP, and respiratory cycle time. Our finding of low MAP leading to extubation failure may be explained by a dyspneic patient with vigorous efforts. Mean airway pressure is a pressure monitoring metric used by mechanical ventilators that are closely connected to mean alveolar pressure and depict pressures on the lung parenchyma during ventilation (41). It's also connected to the oxygenation index (42). Peak inspiratory pressure, PEEP, and the inspiratory-to-expiratory time ratio with dynamic and real-time features are used to calculate MAP, which measures mechanical power impacted by the ventilator mode (43). A high MAP suggests that the patient's mechanical energy power is greater (43). Furthermore, MAP is a critical pressure parameter that influences a patient's hemodynamics. It has been established that higher MAP causes a reduction in cardiac output in infants during both normal and high-frequency mechanical 


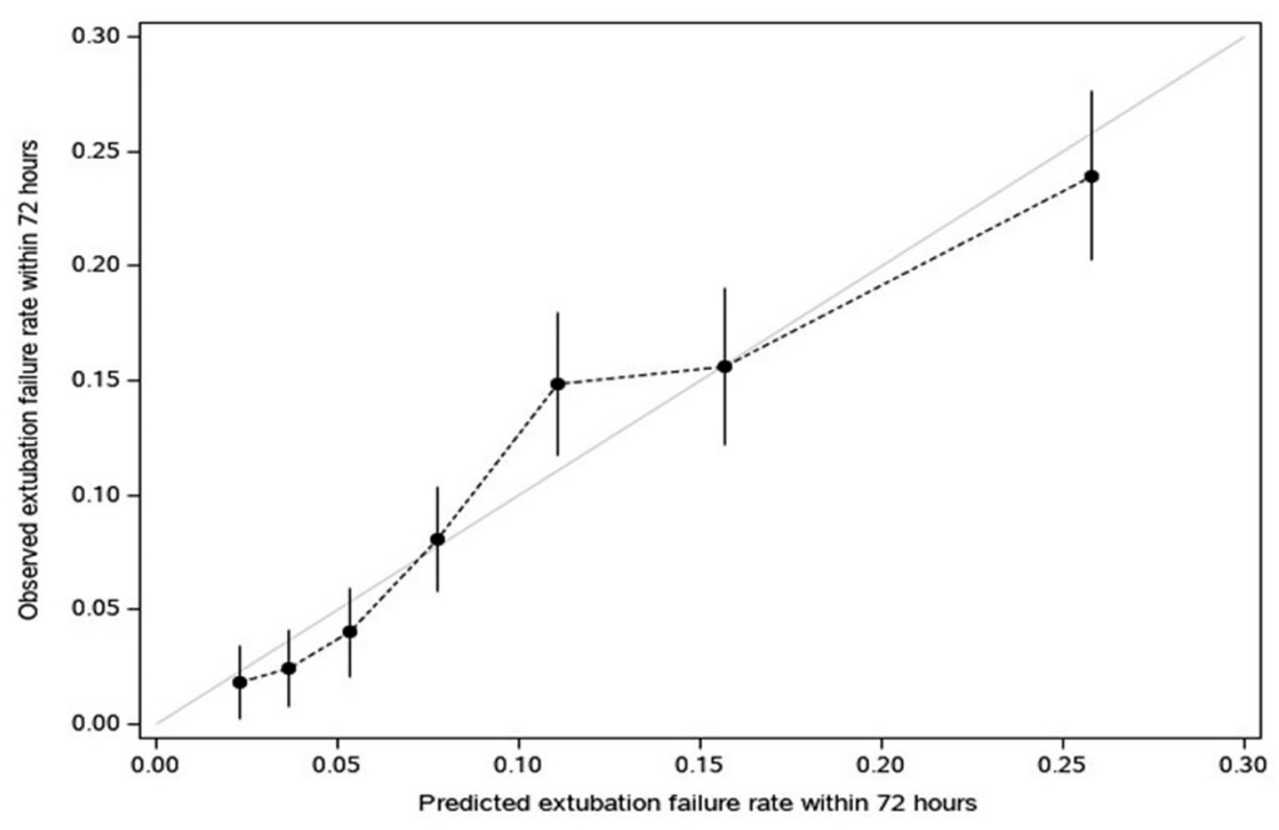

FIGURE 3 | Calibration plot of observed vs. predicted extubation failure in the validation set (dots convey the apparent calibration from the original model, in which predictions for extubation failure within $72 \mathrm{~h}$ are grouped into deciles (10 groups ranging from low to high likelihood) and each related to observed rates (vertical bars reflect $95 \% \mathrm{Cl}$ for the rate); For a reference of perfect calibration, the $\mathrm{Y}=\mathrm{X}$ line is displayed).
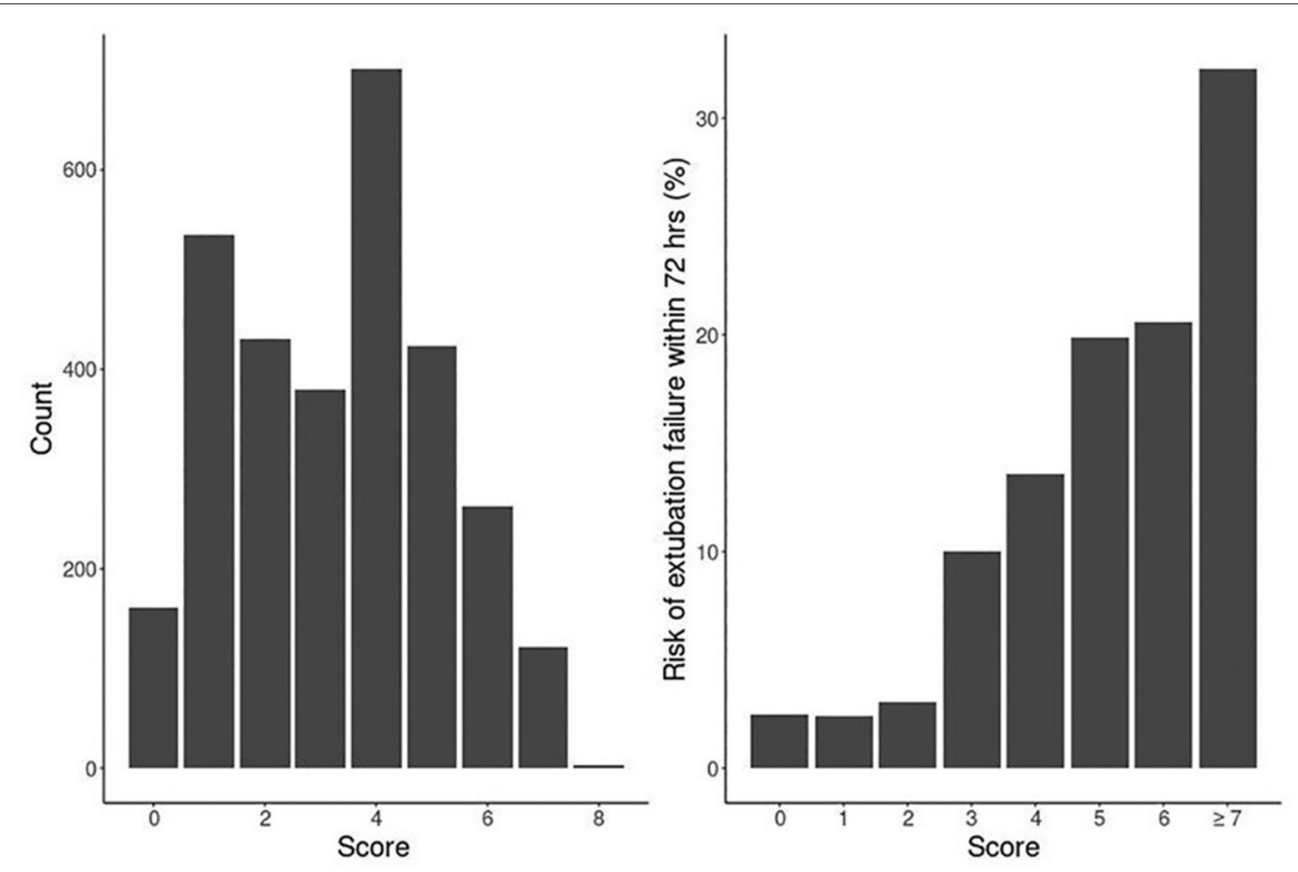

FIGURE 4 | Distribution of RISC score and the corresponding 72-h extubation failure rate (\%).

ventilation $(44,45)$. In direct proportion to their effects on MAP, tidal forces and PEEP raise pulmonary vascular resistance (PVR) (46). As a result, MAP is becoming more linked to the prognosis of patients on mechanical ventilation. A patient that is not able to mount a high MAP may demonstrate insufficient respiratory mechanics from possibly, diaphragmatic weakness. Patients who are able to mount a high MAP may have more strength in respiratory muscles, and thus mechanics, thereby resulting in tolerance of extubation. In summary, we argue that MAP has several strengths over other conventional 
mechanical ventilator parameters especially pressure indicators, and it has the ability to become a major bridge factor coupling respiratory mechanics and hemodynamics. However, we acknowledge there are factors potentially not assessed in this study during the transition from positive to negative pressure physiology, stressors on cardiac physiology, and potentially $\mathrm{CO}_{2}$ accumulation that could theoretically occur before extubation.

Thille et al. (33) identified prolonged mechanical ventilation (duration $<1$ week) prior to weaning as a strong predictor for $\mathrm{EF}$, similar to our results. We observed that underweight status was also associated with EF and an important factor since it underlies neuromuscular reserve. Malnutrition is reported in as much as $40 \%$ of critically ill patients, but data linking nutritional status to ventilator weaning issues are limited $(47,48)$. In the acute respiratory distress syndrome (ARDS) network trial (43); $4.7 \%$ of patients were identified as underweight. Underweight patients, defined as those with a body mass index $<18.5 \mathrm{~kg} / \mathrm{m}^{2}$, may experience depressed ventilatory drive (49), limited muscle mass (50), and weaning difficulty (51). Obesity may be associated with a better prognosis ("obesity paradox") for some disease states, patients with ARDS (52) and those in the ICU in general $(53,54)$. Another important covariate in EF was positive fluid balance, as reported by Frutos-Vivar et al. (27). This is an important finding for clinicians to review prior to extubation attempts since diuretics could be given in future RISC-driven randomized trials on EF. D'Orio et al. (55) reported that a positive cumulative fluid balance may cause increased capillary leak and extravascular lung water and decreased lung compliance, leading to respiratory failure, both during SBT and in the immediate post-extubation period. Hence why restrictive fluid strategies are employed in ARDS patients (56). In an earlier study, positive cumulative fluid balance from hospital admission to weaning was correlated with $\mathrm{EF}$ (57). Therefore, it is highly plausible that positive fluid balance influences the respiratory outcome of patients.

To our knowledge, there are no comprehensive data sets analyzing all the variables we proposed in predicting ES, particularly with neurologic components. Most studies focus on RSBI as a predictor in the post-operative setting $(27,37,58)$. RSBI is challenging however in patients in pain with tachypnea and some neurologic patients with abnormal brain-disordered breathing states. The closest study we found in the literature similar to ours was a neonatal extubation modeling study by Mueller et al. (54), who used artificial neural-networks, receiver operating characteristics, and regression modeling to predict ES. The authors looked at inspiratory to expiratory ratio, inspiratory time, MAP, tidal volume, and $\mathrm{SaO}_{2}$. The authors found an AUC of 0.87 , which is a fairly strong prediction for ES (59). Other studies have studied ES but these have been largely focused on operating room predictors and not global predictors (60). Rodriguez Blanco et al. (60) studied 78 surgery patients who had adequate ejection fraction and other standard clinical factors. This study did not adequately characterize the respiratory variables proposed and was of relatively small sample size. Similarly, data from a cohort of mechanically ventilated elderly patients were prospectively analyzed and used to develop a predictive model using a classification and regressive tree (CART) algorithm, also known as a decision tree to predict extubation outcome in patients following a successful SBT $(29,30)$. This CART model showed a good discrimination with an AUC of 0.94 . However, calibration was moderate with a substantial mismatch between predicted and actual probabilities in the updated CART model (47).

Our study has several limitations. First, the retrospective design limits extrapolation to prospective and individualized patient care contexts. Retrospective studies can introduce selection and information biases. We were also not able to collect data on all clinical weaning predictors such as diaphragm movement, endotracheal secretions, and hypercapnic ventilatory response, Airway occlusion pressure in each patient. Second, our study lacked granular data on supplemental oxygen strategies post-extubation as recent literature supports high flow nasal cannula combined with non-invasive in preventing re-intubation $(61,62)$. Third, the study was completed at a single center with retrospective data collection, and thus does not allow inferences on causality derived from prospective data. Fourth, we were not able to collect echocardiographic measurements to be able to correlate positive fluid balance with ventricular dysfunction. Fifth, in our model, there may be some lack of variability using a retrospective cohort from the same center, and thus validation and accuracy may be overestimated. Sixth, some of the ventilator data captured in this study such as the reporting of a plateau pressure measurement during pressure support in a spontaneously breathing patient were from Puritan Bennett 840 ventilators (Medtronic). These ventilators record into the EMR what it believes are plateau pressures in any mode, even when an adequate inspiratory pause is absent. We have documented instances where vitals are being recorded at greater than the 15 -min standard of the time for procedures or more while ventilator settings remained as they were. Lastly, our multivariate covariates within our RISC score model are generally known single risk factors of $\mathrm{EF}$ in the existing literature $(27,28,33-35,63)$. Therefore, our study should be considered with caution as exploratory only and requires prospective and external validation of the multivariate model before implementing into routine clinical decision making. This is especially true given data is from a single site that may reflect a unique culture not practiced by others.

Despite our limitations, this study has several strengths. A major strength is that it was done using a robust and clean dataset derived from a previously validated database (64). The study also included a large cohort of patients from a large, tertiary academic hospital. To date, there are no comprehensive data sets analyzing all the variables in predicting ES, especially with neurological components; therefore, we feel this study could represent the first adult human modeling study, and by the addition of more variables, an even more potentially accurate and precise model for predicting ES in the future. However, we still recommend external validation before generalizing and implementing these results as predictive models.

\section{CONCLUSIONS}

We developed the RISC score using several practical clinical parameters tested within a derivation and validation set. This 
model provides risk-stratification for extubation and subsequent EF within $72 \mathrm{~h}$ in mechanically ventilated patients in the ICU. Overall, we identified 5 predictors of EF readily available at the bedside and in many EMRs: underweight status (body mass index $<18.5 \mathrm{~kg} / \mathrm{m}^{2}$ ), GCS score $\geq 10$, MAP closest to 1 min after SBT start within $15 \mathrm{~min}<10 \mathrm{cmH}_{2} \mathrm{O}$, fluid balance of $\geq 1,500 \mathrm{~mL}$ $24 \mathrm{~h}$ prior to extubation, and mechanical ventilation $\geq 5$ days. External validation in a larger, multicenter study is required before clinical implementation.

\section{DATA AVAILABILITY STATEMENT}

The original contributions presented in the study are included in the article/Supplementary Material, further inquiries can be directed to the corresponding author/s.

\section{ETHICS STATEMENT}

The studies involving human participants were reviewed and approved by Mayo Clinic Institutional Review Board. Written informed consent for participation was not required for this study in accordance with the national legislation and the institutional requirements.

\section{DISCLOSURE}

Presented at the Neurocritical Care Society 15th Annual Meeting, Waikoloa Village, Hawaii, October 13-17, 2017 and portions

\section{REFERENCES}

1. Yang KL, Tobin MJ. A prospective study of indexes predicting the outcome of trials of weaning from mechanical ventilation. N Engl J Med. (1991) 324:1445-50. doi: 10.1056/NEJM199105233242101

2. Brochard L, Rauss A, Benito S, Conti G, Mancebo J, Rekik N, et al. Comparison of three methods of gradual withdrawal from ventilatory support during weaning from mechanical ventilation. Am J Respir Crit Care Med. (1994) 150:896-903. doi: 10.1164/ajrccm.150.4.7921460

3. Esteban A, Frutos F, Tobin MJ, Alia I, Solsona JF, Valverdu I, et al. A comparison of four methods of weaning patients from mechanical ventilation. Spanish Lung Failure Collaborative Group. N Engl J Med. (1995) 332:345-50. doi: 10.1056/NEJM199502093320601

4. Epstein SK. Decision to extubate. Intensive Care Med. (2002) 28:535-46. doi: 10.1007/s00134-002-1268-8

5. Epstein SK. Extubation failure: an outcome to be avoided. Crit Care. (2004) 8:310-2. doi: $10.1186 / \operatorname{cc} 2927$

6. Torres A, Aznar R, Gatell JM, Jimenez P, Gonzalez J, Ferrer A, et al. Incidence, risk, and prognosis factors of nosocomial pneumonia in mechanically ventilated patients. Am Rev Respir Dis. (1990) 142:523-8. doi: 10.1164/ajrccm/142.3.523

7. Torres A, Gatell JM, Aznar E, el-Ebiary M, Puig de la Bellacasa J, Gonzalez $\mathrm{J}$, et al. Re-intubation increases the risk of nosocomial pneumonia in patients needing mechanical ventilation. Am J Respir Crit Care Med. (1995) 152:13741. doi: 10.1164/ajrccm.152.1.7599812

8. Coplin WM, Pierson DJ, Cooley KD, Newell DW, Rubenfeld GD. Implications of extubation delay in brain-injured patients meeting standard weaning criteria. Am J Respir Crit Care Med. (2000) 161:1530-6. doi: 10.1164/ajrccm.161.5.9905102

9. Manno EM, Rabinstein AA, Wijdicks EF, Brown AW, Freeman WD, Lee $\mathrm{VH}$, et al. A prospective trial of elective extubation in brain injured patients of this manuscript have been published in abstract form and available online at https://link.springer.com/journal/12028/ volumes-and-issues/27-2/supplement and citation "Bansal V, Li Z, Marquez A, Kashyap R, Smelick CP, Diaz-Gomez JL, et al. Re-Intubation Scale Calculation (RISC): predicting extubation failure in critically ill patients. Neurocritical Care. (2017) 27(Suppl. 2):S122.”

\section{AUTHOR CONTRIBUTIONS}

$\mathrm{VB}$, NS, RK, and WF contributed to the conception and design of the study. $\mathrm{VB}$ and $\mathrm{AM}$ organized the database. VB and $\mathrm{ZL}$ performed the statistical analysis. All authors contributed to the article and approved the submitted version.

\section{FUNDING}

This work was supported by the Department of Neurology at Mayo Clinic, Jacksonville, Florida with no direct funding.

\section{SUPPLEMENTARY MATERIAL}

The Supplementary Material for this article can be found online at: https://www.frontiersin.org/articles/10.3389/fmed. 2021.789440/full\#supplementary-material meeting extubation criteria for ventilatory support: a feasibility study. Crit Care. (2008) 12:R138. doi: 10.1186/cc7112

10. Epstein SK, Ciubotaru RL, Wong JB. Effect of failed extubation on the outcome of mechanical ventilation. Chest. (1997) 112:186-92. doi: 10.1378/chest.112.1.186

11. Esteban A, Alia I, Gordo F, Fernandez R, Solsona JF, Vallverdu I, et al. Extubation outcome after spontaneous breathing trials with T-tube or pressure support ventilation. The Spanish Lung Failure Collaborative Group. Am J Respir Crit Care Med. (1997) 156(2 Pt 1):459-65. doi: 10.1164/ajrccm.156.2.9610109

12. Esteban A, Alia I, Tobin MJ, Gil A, Gordo F, Vallverdu I, et al. Effect of spontaneous breathing trial duration on outcome of attempts to discontinue mechanical ventilation. Spanish Lung Failure Collaborative Group. Am J Respir Crit Care Med. (1999) 159:512-8. doi: 10.1164/ajrccm.159.2.9803106

13. Frutos-Vivar F, Esteban A, Apezteguia C, Gonzalez M, Arabi Y, Restrepo MI, et al. Outcome of reintubated patients after scheduled extubation. J Crit Care. (2011) 26:502-9. doi: 10.1016/j.jcrc.2010.12.015

14. Meade M, Guyatt G, Cook D, Griffith L, Sinuff T, Kergl C, et al. Predicting success in weaning from mechanical ventilation. Chest. (2001) 120(6 Suppl.):400S-24. doi: 10.1378/chest.120.6_suppl.400S

15. MacIntyre NR, Cook DJ, Ely EW Jr, Epstein SK, Fink JB, Heffner JE, et al. Evidence-based guidelines for weaning and discontinuing ventilatory support: a collective task force facilitated by the American College of Chest Physicians; the American Association for Respiratory Care; and the American College of Critical Care Medicine. Chest. (2001) 120(6 Suppl.):375S-95. doi: 10.1378/chest.120.6_suppl.375S

16. Salam A, Tilluckdharry L, Amoateng-Adjepong Y, Manthous CA. Neurologic status, cough, secretions and extubation outcomes. Intensive Care Med. (2004) 30:1334-9. doi: 10.1007/s00134-004-2231-7

17. El Solh AA, Bhat A, Gunen H, Berbary E. Extubation failure in the elderly. Respir Med. (2004) 98:661-8. doi: 10.1016/j.rmed.2003.12.010 
18. Smina M, Salam A, Khamiees M, Gada P, Amoateng-Adjepong Y, Manthous CA. Cough peak flows and extubation outcomes. Chest. (2003) 124:262-8. doi: 10.1378/chest.124.1.262

19. Namen AM, Ely EW, Tatter SB, Case LD, Lucia MA, Smith A, et al. Predictors of successful extubation in neurosurgical patients. Am J Respir Crit Care Med. (2001) 163(3 Pt 1):658-64. doi: 10.1164/ajrccm.163.3.2003060

20. Khamiees M, Raju P, DeGirolamo A, Amoateng-Adjepong Y, Manthous CA. Predictors of extubation outcome in patients who have successfully completed a spontaneous breathing trial. Chest. (2001) 120:1262-1270. doi: 10.1378/chest.120.4.1262

21. Tobin MJ, Perez W, Guenther SM, Semmes BJ, Mador MJ, Allen SJ, et al. The pattern of breathing during successful and unsuccessful trials of weaning from mechanical ventilation. Am Rev Respir Dis. (1986) 134:1111-8.

22. Jubran A, Parthasarathy S. Hypercapnic respiratory failure during weaning: neuromuscular capacity versus muscle loads. Respir Care Clin N Am. (2000) 6:385-405. doi: 10.1016/S1078-5337(05)70078-2

23. Dunn WF, Nelson SB, Hubmayr RD. The control of breathing during weaning from mechanical ventilation. Chest. (1991) 100:754-61. doi: $10.1378 /$ chest.100.3.754

24. Prechter GC, Nelson SB, Hubmayr RD. The ventilatory recruitment threshold for carbon dioxide. Am Rev Respir Dis. (1990) 141:758-64. doi: 10.1164/ajrccm/141.3.758

25. Ferrer M, Valencia M, Nicolas JM, Bernadich O, Badia JR, Torres A. Early noninvasive ventilation averts extubation failure in patients at risk: a randomized trial. Am J Respir Crit Care Med. (2006) 173:164-70. doi: 10.1164/rccm.200505-718OC

26. Herasevich V, Kor DJ, Li M, Pickering BW. ICU data mart: a non-iT approach. A team of clinicians, researchers and informatics personnel at the Mayo Clinic have taken a homegrown approach to building an ICU data mart. Healthc Inform. (2011) 28:42, 44-5.

27. Frutos-Vivar F, Ferguson ND, Esteban A, Epstein SK, Arabi Y, Apezteguia $\mathrm{C}$, et al. Risk factors for extubation failure in patients following a successful spontaneous breathing trial. Chest. (2006) 130:1664-71. doi: $10.1378 /$ chest.130.6.1664

28. Godet T, Chabanne R, Marin J, Kauffmann S, Futier E, Pereira B, et al. Extubation Failure in Brain-injured Patients: risk factors and development of a prediction score in a preliminary prospective cohort study. Anesthesiology. (2017) 126:104-14. doi: 10.1097/ALN.0000000000001379

29. Liu Y, Mu YU, Li GQ, Yu X, Li PJ, Shen ZQ, et al. Extubation outcome after a successful spontaneous breathing trial: a multicenter validation of a 3-factor prediction model. Exp Ther Med. (2015) 10:1591-601. doi: 10.3892/etm.2015.2678

30. Liu Y, Wei LQ, Li GQ, Lv FY, Wang H, Zhang YH, et al. A decisiontree model for predicting extubation outcome in elderly patients after a successful spontaneous breathing trial. Anesth Analg. (2010) 111:1211-8. doi: 10.1213/ANE.0b013e3181f4e82e

31. Steyerberg EW, Eijkemans MJ, Harrell FE Jr, Habbema JD. Prognostic modelling with logistic regression analysis: a comparison of selection and estimation methods in small data sets. Stat Med. (2000) 19:1059-79. doi: 10.1002/(SICI)1097-0258(20000430)19:8\&lt;1059::AIDSIM412\&gt;3.0.CO;2-0

32. Steyerberg EW, Eijkemans MJ, Harrell FE Jr, Habbema JD. Prognostic modeling with logistic regression analysis: in search of a sensible strategy in small data sets. Med Decis Making. (2001) 21:45-56. doi: 10.1177/0272989X0102100106

33. Thille AW, Boissier F, Ben Ghezala H, Razazi K, Mekontso-Dessap A, BrunBuisson C. Risk factors for and prediction by caregivers of extubation failure in ICU patients: a prospective study. Crit Care Med. (2015) 43:613-20. doi: 10.1097/CCM.0000000000000748

34. Thille AW, Harrois A, Schortgen F, Brun-Buisson C, Brochard L. Outcomes of extubation failure in medical intensive care unit patients. Crit Care Med. (2011) 39:2612-8. doi: 10.1097/CCM.0b013e3182282a5a

35. Thille AW, Richard JC, Brochard L. The decision to extubate in the intensive care unit. Am J Respir Crit Care Med. (2013) 187:1294-302. doi: 10.1164/rccm.201208-1523CI

36. Zeggwagh AA, Abouqal R, Madani N, Zekraoui A, Kerkeb O. Weaning from mechanical ventilation: a model for extubation. Intensive Care Med. (1999) 25:1077-83. doi: 10.1007/s001340051015
37. Mokhlesi B, Tulaimat A, Gluckman TJ, Wang Y, Evans AT, Corbridge TC. Predicting extubation failure after successful completion of a spontaneous breathing trial. Respir Care. (2007) 52:1710-7.

38. Chevron V, Menard JF, Richard JC, Girault C, Leroy J, Bonmarchand G. Unplanned extubation: risk factors of development and predictive criteria for reintubation. Crit Care Med. (1998) 26:1049-53. doi: 10.1097/00003246-199806000-00026

39. Vallverdu I, Calaf N, Subirana M, Net A, Benito S, Mancebo J. Clinical characteristics, respiratory functional parameters, and outcome of a two-hour T-piece trial in patients weaning from mechanical ventilation. Am J Respir Crit Care Med. (1998) 158:1855-62. doi: 10.1164/ajrccm.158.6.9712135

40. Wijdicks EF, Bamlet WR, Maramattom BV, Manno EM, McClelland RL. Validation of a new coma scale: the FOUR score. Ann Neurol. (2005) 58:58593. doi: 10.1002/ana.20611

41. Marini JJ, Ravenscraft SA. Mean airway pressure: physiologic determinants and clinical importance-Part 1: physiologic determinants and measurements. Crit Care Med. (1992) 20:1461-72. doi: 10.1097/00003246-199210000-00017

42. Trachsel D, McCrindle BW, Nakagawa S, Bohn D. Oxygenation index predicts outcome in children with acute hypoxemic respiratory failure. Am J Respir Crit Care Med. (2005) 172:206-11. doi: 10.1164/rccm.200405-625OC

43. Gattinoni L, Tonetti T, Cressoni M, Cadringher P, Herrmann P, Moerer O, et al. Ventilator-related causes of lung injury: the mechanical power. Intensive Care Med. (2016) 42:1567-75. doi: 10.1007/s00134-016-4505-2

44. Gullberg N, Winberg P, Sellden H. Changes in stroke volume cause change in cardiac output in neonates and infants when mean airway pressure is altered. Acta Anaesthesiol Scand. (1999) 43:999-1004. doi: 10.1034/j.1399-6576.1999.431005.x

45. Gullberg N, Winberg P, Sellden H. Changes in mean airway pressure during HFOV influences cardiac output in neonates and infants. Acta Anaesthesiol Scand. (2004) 48:218-23. doi: 10.1111/j.1399-6576.2004.00299.x

46. Luecke T, Pelosi P. Clinical review: positive end-expiratory pressure and cardiac output. Crit Care. (2005) 9:607-21. doi: 10.1186/cc3877

47. Tremblay A, Bandi V. Impact of body mass index on outcomes following critical care. Chest. (2003) 123:1202-1207. doi: 10.1378/chest.123.4.1202

48. Boles JM, Bion J, Connors A, Herridge M, Marsh B, Melot C, et al. Weaning from mechanical ventilation. Eur Respir J. (2007) 29:1033-56. doi: 10.1183/09031936.00010206

49. Doekel RC Jr, Zwillich CW, Scoggin CH, Kryger M, Weil JV. Clinical semistarvation: depression of hypoxic ventilatory response. N Engl J Med. (1976) 295:358-61. doi: 10.1056/NEJM197608122950703

50. Akazawa N, Harada K, Okawa N, Tamura K, Moriyama H. Low body mass index negatively affects muscle mass and intramuscular fat of chronic stroke survivors. PLoS One. (2019) 14:e0211145. doi: 10.1371/journal.pone.0211145

51. Esquinas AM. Noninvasive Mechanical Ventilation and Difficult Weaning in Critical Care: Key Topics and Practical Approaches. Switzerland: Springer International Publishing (2016). doi: 10.1007/978-3-319-04259-6

52. De Jong A, Carreira S, Na N, Carillion A, Jiang C, Beuvin M, et al. Diaphragmatic function is enhanced in fatty and diabetic fatty rats. PLoS ONE. (2017) 12:e0174043. doi: 10.1371/journal.pone.0174043

53. De Jong A, Verzilli D, Sebbane M, Monnin M, Belafia F, Cisse M, et al. Medical versus surgical ICU obese patient outcome: a propensity-matched analysis to resolve clinical trial controversies. Crit Care Med. (2018) 46:e294-301. doi: 10.1097/CCM.0000000000002954

54. Jaber S, Quintard H, Cinotti R, Asehnoune K, Arnal JM, Guitton C, et al. Risk factors and outcomes for airway failure versus non-airway failure in the intensive care unit: a multicenter observational study of 1514 extubation procedures. Crit Care. (2018) 22:236. doi: 10.1186/s13054-018-2150-6

55. D'Orio V, Mendes P, Carlier P, Fatemi M, Marcelle R. Lung fluid dynamics and supply dependency of oxygen uptake during experimental endotoxic shock and volume resuscitation. Crit Care Med. (1991) 19:955-62. doi: 10.1097/00003246-199107000-00022

56. Wiedemann HP, Wheeler AP, Bernard GR, Thompson BT, Hayden D, deBoisblanc B, et al. Comparison of two fluid-management strategies in acute lung injury. N Engl J Med. (2006) 354:2564-75. doi: 10.1016/j.jvs.2006. 08.053

57. Upadya A, Tilluckdharry L, Muralidharan V, Amoateng-Adjepong Y, Manthous CA. Fluid balance and weaning outcomes. Intensive Care Med. (2005) 31:1643-1647. doi: 10.1007/s00134-005-2801-3 
58. Bien MY, Shui Lin Y, Shih CH, Yang YL, Lin HW, Bai KJ, et al. Comparisons of predictive performance of breathing pattern variability measured during T-piece, automatic tube compensation, and pressure support ventilation for weaning intensive care unit patients from mechanical ventilation. Crit Care Med. (2011) 39:2253-62. doi: 10.1097/CCM.0b013e31822279ed

59. Mueller M, Wagner CL, Annibale DJ, Hulsey TC, Knapp RG, Almeida JS. Predicting extubation outcome in preterm newborns: a comparison of neural networks with clinical expertise and statistical modeling. Pediatr Res. (2004) 56:11-8. doi: 10.1203/01.PDR.0000129658.55746.3C

60. Rodriguez Blanco YF, Candiotti K, Gologorsky A, Tang F, Giquel J, Barron ME, et al. Factors which predict safe extubation in the operating room following cardiac surgery. J Cardiac Surg. (2012) 27:275-80. doi: 10.1111/j.1540-8191.2012.01434.x

61. Thille AW, Muller G, Gacouin A, Coudroy R, Decavele M, Sonneville R, et al. Effect of postextubation high-flow nasal oxygen with noninvasive ventilation vs high-flow nasal oxygen alone on reintubation among patients at high risk of extubation failure: a randomized clinical trial. JAMA. (2019) 322:1465-75. doi: 10.1001/jama.2019.14901

62. Hernandez G, Vaquero C, Colinas L, Cuena R, Gonzalez P, Canabal A, et al. Effect of postextubation high-flow nasal cannula vs noninvasive ventilation on reintubation and postextubation respiratory failure in highrisk patients: a randomized clinical trial. JAMA. (2016) 316:1565-74. doi: 10.1001/jama.2016.14194

63. Gerbaud E, Erickson M, Grenouillet-Delacre M, Beauvieux MC, Coste P, Durrieu-Jais C, et al. Echocardiographic evaluation and N-terminal probrain natriuretic peptide measurement of patients hospitalized for heart failure during weaning from mechanical ventilation. Minerva Anestesiol. (2012) 78:415-25.

64. Kashyap R, Singh TD, Rayes H, O'Horo JC, Wilson G, Bauer $\mathrm{P}$, et al. Association of septic shock definitions and standardized mortality ratio in a contemporary cohort of critically ill patients. J Crit Care. (2019) 50:269-74. doi: 10.1016/j.jcrc.2019. 01.005

Conflict of Interest: The authors declare that the research was conducted in the absence of any commercial or financial relationships that could be construed as a potential conflict of interest.

Publisher's Note: All claims expressed in this article are solely those of the authors and do not necessarily represent those of their affiliated organizations, or those of the publisher, the editors and the reviewers. Any product that may be evaluated in this article, or claim that may be made by its manufacturer, is not guaranteed or endorsed by the publisher.

Copyright (c) 2022 Bansal, Smischney, Kashyap, Li, Marquez, Diedrich, Siegel, Sen, Tomlinson, Venegas-Borsellino and Freeman. This is an open-access article distributed under the terms of the Creative Commons Attribution License (CC BY). The use, distribution or reproduction in other forums is permitted, provided the original author(s) and the copyright owner(s) are credited and that the original publication in this journal is cited, in accordance with accepted academic practice. No use, distribution or reproduction is permitted which does not comply with these terms. 